Research Article

\title{
A Perspective Analysis of Dams and Water Quality: The Bui Power Project on the Black Volta, Ghana
}

\author{
Samuel Fosu Gyasi $\mathbb{D}^{1},{ }^{1}$ Bismark Boamah, ${ }^{2}$ Esi Awuah, ${ }^{3}$ and Kenneth Bentum Otabil $\mathbb{D}^{1}$ \\ ${ }^{1}$ Department of Basic and Applied Biology, School of Science, University of Energy and Natural Resources, Sunyani, Ghana \\ ${ }^{2}$ Department of Energy and Environmental Engineering, School of Engineering, University of Energy and Natural Resources, \\ Sunyani, Ghana \\ ${ }^{3}$ Department of Civil Engineering, School of Engineering, Kwame Nkrumah University of Science and Technology, \\ Kumasi, Ghana
}

Correspondence should be addressed to Samuel Fosu Gyasi; samuel.gyasi.fosu@gmail.com

Received 21 June 2018; Revised 21 August 2018; Accepted 13 September 2018; Published 1 October 2018

Academic Editor: Stefano Capolongo

Copyright (c) 2018 Samuel Fosu Gyasi et al. This is an open access article distributed under the Creative Commons Attribution License, which permits unrestricted use, distribution, and reproduction in any medium, provided the original work is properly cited.

\begin{abstract}
Large dams play an important role in promoting economic and social development in many countries. However, the construction of such dams can have a detrimental effect on the environment. The aim of this study was to investigate perceptions of drinking water quality among inhabitants of selected communities within the Bui Dam environs. With the help of questionnaires, 100 respondents from communities "near to the dam" were randomly selected and interviewed. Their responses were compared with another 100 respondents selected from "far from the dam" communities. These were augmented with indepth interviews, focus group discussion, and personal observation. Analysis of the results showed that, there were greater proportions (31\%) of the participants who lived in "near communities" within the age category $20-25$ compared to $19 \%$ of their "far communities" counterparts. There were significantly greater proportions of female respondents in the "near to the dam" (57\%) compared to respondents in the "far from the dam" communities (52\%). The study further showed that the perception of risk of consuming contaminated drinking water was more common among "far from the dam" communities (odds ratio $=4.57$ ). The perception of the quality of water based on some physical properties was investigated as part of our study. Analysis of the results showed that significantly greater proportion of the "far from the dam" communities (35\%) perceived their water had an objectionable smell compared to $7 \%$ of inhabitants of their other counterparts ( $p$ value $=0.001$ ). The study further showed that significantly greater proportion of the study participants in the far from the communities perceived that their water had colour (65\%) and they did not drink water from any other source (63\%) apart from their stream. The study demonstrated that generally, inhabitants within the study communities perceived the construction of the Bui Power Project has negatively affected their drinking water quality.
\end{abstract}

\section{Introduction}

Development of rivers for large dams have emerged as one of the most significant and visible tools for the management of water resources [1]. Large dams play an important role as they promote economic and social development. They also provide important services such as electricity generation, water supplies, and flood control [2]. However, proposals for new dams in many countries have aroused intense opposition [3] with many social and economic arguments used against its construction. A major reason for such arguments is the fact that large dams produce major ecological changes in river ecosystems [3]. Dams have impacts on both upstream and downstream ecosystems [4]. They constitute obstacles for longitudinal exchange along rivers and disrupt many natural environmental processes. Flooding upstream of dams results in the permanent destruction of terrestrial ecosystems through inundation. All terrestrial plants and animals disappear from the submerged area [4].

For some time now, flooding of dam has created a plethora of disturbances in the ecosystem, varying from enormous ecological and productivity related changes [5]. 
This massive land modification occurs according to the physical and biological characteristics of the site and the management regime of the dam. Floods have the tendency to cause hydraulic disturbances that determine the composition of biotic communities within the channel, the riparian zone and the flood plain [6]. Water storage in reservoirs induces physical, chemical, and biological changes in stored water. Elsewhere during arid climates, water below dam causes salinization arising from increased evaporation and particularly problematic in areas of marine sediments.

Since 1965, the government of Ghana started the construction of Akosombo Dam, forming Lake Volta, the largest water storage reservoir in Africa and even the world [7]. This dam provided the energy needs of a then growing country with relatively fewer people and less industries. In more recent years, due to rapid population growth, industrialization, and urbanization, a serious energy deficit has emerged. This resulted in an urgent need to build another hydroelectric power dam, the Bui Hydroelectric Dam to reduce the deficit. Upon completion, the Bui Hydroelectric Dam generates electricity and, in addition, supplies water for domestic and industrial uses. In addition, water is harvested from this dam to irrigate agricultural lands to boost food production. However, the benefits of this project cannot be without considerable social, economic, and environmental costs, as has been the case with dams elsewhere in the world and even with the Kpong and Akosombo Dams in Ghana. Meanwhile, following the completion and operation of the Bui Dam, there has been numerous reports by some sections of the media and some major stakeholders that some inhabitants living close to the Bui Hydroelectric Project area perceive that the quality of their drinking water has been compromised. Till date, there are no empirical data in published articles to ascertain the veracity of this assertion by inhabitants of the Bui dam environs although different research conducted by other investigators in other regions supports such assertion $[8,9]$. There is therefore an urgent need for a study such as this to investigate the perception of inhabitants on drinking water quality of some surface water after the construction of the Bui Dam. The main aim of this study therefore was to investigate the perception of the quality of drinking water among inhabitants of some selected communities within the Bui Dam environs. These perceptions are important as they can influence the relationship between the dam operators and the host community. This study will also provide the basis for studies to investigate those perceptions.

\section{Materials and Methods}

2.1. Study Area and Population. The study was carried out within some selected communities upstream and downstream of the Bui Dam environ in the Bole district (northern region) and the Banda-Ahenkro district (Brong-Ahafo Region) in north-western Ghana, approximately $150 \mathrm{~km}$ upstream of Lake Volta. The study area lies between latitudes $8^{\circ} 09^{\prime}-8^{\circ} .16^{\prime}$ North and $2^{\circ} 01^{\prime}-2^{\circ}$. $15^{\prime}$ longitude West. The vegetation in the Bui area consists of about $60 \%$ savannah woodland, $10 \%$ riparian forest, and $30 \%$ grassland. There are about 45 communities surrounding the Bui Hydropower project with an estimated population of about 29,287. The most dominant occupation of the inhabitants is fishing [10].

2.2. Selection of Study Communities. Communities for the study were systematically selected based on their farness or closeness to the dam. These included Agblekame South, Bongase Nsuo-Ano (Banda-Ahenkro), and Agblekame North, Gyama Nsuo-Ano (Bole Bamboi), as shown in Figure 1 below.

2.3. Study Design and Communities Selection. The study adopted a longitudinal study approach with responses from respondents domiciled in close communities compared with those of their far community counterparts. On the basis of this, Agblekame South and Agblekame North were designated to be the "far communities" while Gyama Nsuo-Ano and Bongase Nsuo-Ano were designated as "near communities."

2.4. Study Methodology. The study used a combination of desk studies, checklists, and interviews to collect primary data. With the help of house to house visits, respondents were randomly selected and interviewed. Structured questionnaires designed for respondents included both open and closed-ended. A total of 200 questionnaires were administered to respondents from the 4 communities with an approximate population size of 2,400 inhabitants during the entire study. Hundred (100) questionnaires were administered randomly to interview respondents selected from the near communities whose responses were compared with another 100 selected from their far communities counterpart. The questions asked were based on sociodemographics, household water usage patterns, and households' hygienic behaviour as perceived by respondents (Lagardere, 2007). These were augmented with in-depth interviews, focus group discussions (FGDs), and personal observation. The use of multiple complimentary methods made it possible to triangulate and eliminate bias that could occur if only one method was employed (Adubofour et al., 2012). The study was conducted between January and June 2015. Respondents were interviewed in Twi (the predominant local language of the inhabitants), and these were later transcribed into English language.

\section{Data Analysis}

Data from answered questionnaires were manually entered in Microsoft Excel (2013). With the help of GraphPad Prism 5 software, categorical variables were analysed using chisquare at $95 \%$ confidence interval with $p$ value $\leq 0.05$ considered significant. Using Linear regression odds ratio (OR), the "perceptions" in terms of the measure of association between a possible exposure and a perceived risk were estimated. 


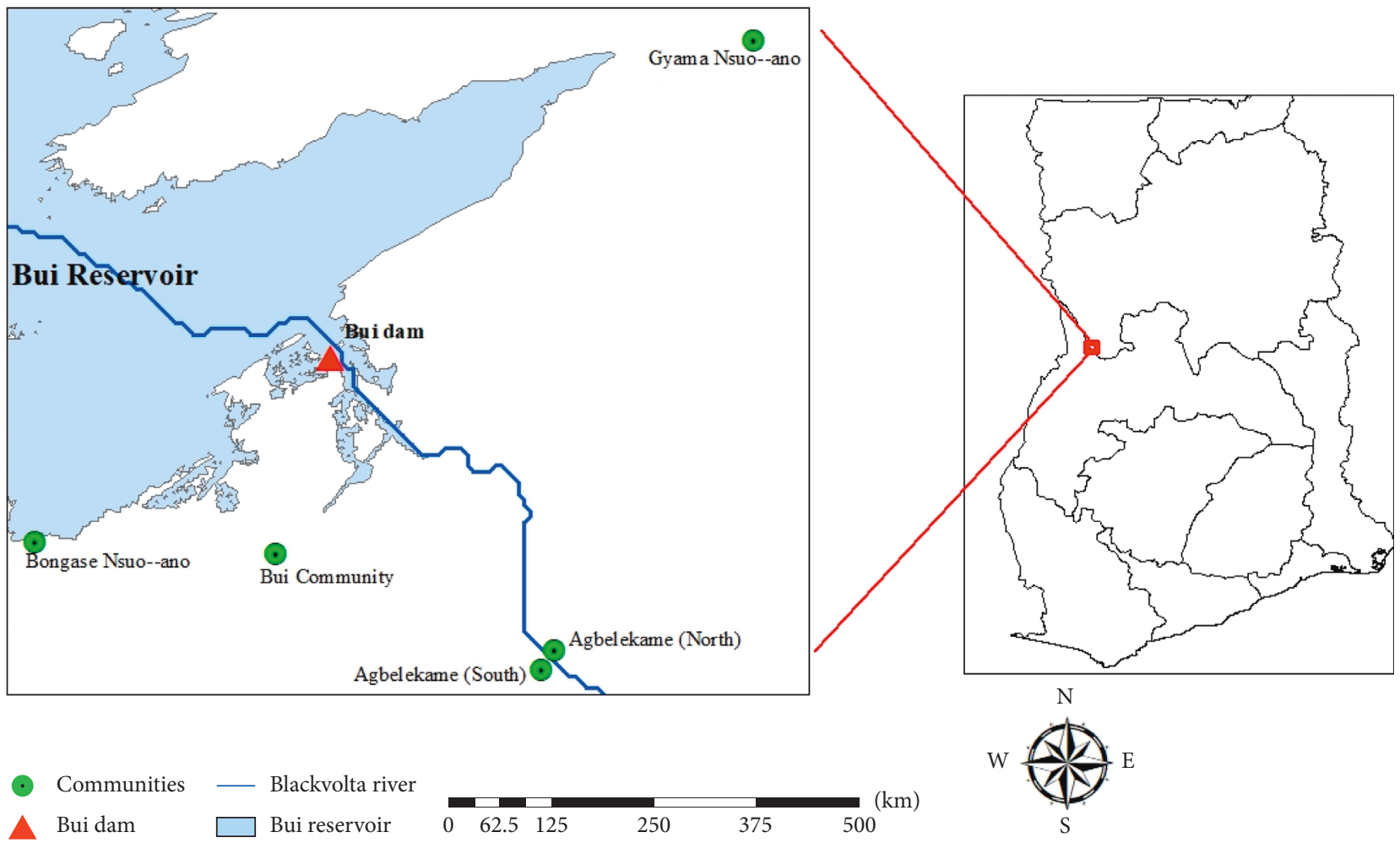

FIGURE 1: Showing the GPS location of study communities where samples were taken.

\section{Results}

In this study, the social demography of respondents was assessed based on ones' location with respect to the Bui Dam. Analysis of the results showed that there were greater proportions $(31 \%)$ of the participants who lived in "near communities" that fell within the age category 20-25 compared to $19 \%$ of their "far communities" counterparts (Table 1). A greater proportion of the "close to the dam" communities respondents (12\%) were adults (aged over 50) compared to their counterpart from the far from the dam communities although the difference was not significant. In terms of gender, there were significantly greater number of female respondents in the "near to the dam" (57\%) compared to respondents in the "far from the dam" communities (52\%) as shown in Table 1 below. Analysis of the marital status of the respondents in the study showed greater proportions $(67 \%)$ of respondents from Bole (near to the dam) being married compared to only $43 \%$ of their BandaAhenkro (far from the dam) counterparts $(p$ value $=0.0006)$ as shown in Table 1 below.

Analysis of the level of education of respondents based on whether a respondents was living near or far from the Bui dam was assessed. Results of the analysis showed that, fewer proportions of respondents in the Banda-Ahenkro (far from the dam) (25\%) had some form of basic education (primary education) compared to their Bole district counterpart (near to the dam) $(47 \%)$ and this was significant $(p=0.012)$ with an odds ratio of 3.8 (Table 1). The study investigated the occupation of respondents based on one's location with respect to the dam and analysis of the results showed that, significantly greater portion of respondents from "near to the dam" communities (65\%) were fishermen compared to $49 \%$ of "far from the dam" downstream community respondents $(49 \%)$ (Table 1$)(p=0.022)$ as shown in Table 1 below.

The study further showed that the perception of risk of consuming contaminated drinking water was more common among "far from the dam" communities due to their location from the dam (odds ratio $=4.57$ ) compared to those of the "close to the dam" communities (Table 1).

The study further investigated the general perception of drinking water quality of respondents in selected communities in the 2 districts, i.e., Banda-Ahenkro (far from the dam) and Bole district in the Brong Ahafo (near to the dam) and Northern regions, respectively. To achieve this, the study investigated the source of water for drinking and for domestic purposes of respondents from both near and far communities. Analysis of the responses showed that a greater proportion (87\%) of the "far from the dam" communities relied on water from streams in their communities compared to of their "near to the dam" counterparts (67\%) as shown in Table 2 below, and this was significant $(p$ value $=0.0008)$. With respect to the reason for their choice of drinking water sources, $39 \%$ of "far from the dam" inhabitants' perceived proximity as the deciding factor compared to only $23 \%$ of inhabitants from the "near to the dam" communities (Table 2).

When respondents in the study were asked whether or not their source of drinking water was treated, the results showed that respondents from the "far from the dam" communities were perceived to be about 5 times at risk 
TABLE 1: Respondent demographic data stratified by location in the Banda and Bole Districts of Ghana.

\begin{tabular}{|c|c|c|c|c|c|}
\hline Variables & $\begin{array}{l}\% \text { total } \\
(200)\end{array}$ & $\begin{array}{l}\% \text { far from the dam } \\
\text { communities }(100)\end{array}$ & $\%$ near to the dam communities $(100)$ & $p$ value & Odds ratio $(\mathrm{OR})$ \\
\hline \multicolumn{6}{|l|}{ Age } \\
\hline Less than 20 & $10(5.0)$ & $3(3.0)$ & $7(7.0)$ & 0.194 & 0.41 \\
\hline $20-25$ & $50(15.0)$ & $19(19.0)$ & $31(31.0)$ & 0.05 & 0.522 \\
\hline $26-30$ & $52(16.0)$ & $20(20.0)$ & $32(32.0)$ & 0.053 & 0.37 \\
\hline $36-40$ & $39(19.5)$ & $15(15.0)$ & $24(24.0)$ & 0.108 & 0.558 \\
\hline $46-50$ & $17(8.5)$ & $8(8.0)$ & $9(9.0)$ & 0.7998 & 0.879 \\
\hline Over 50 & $32(16.0)$ & $12(12.0)$ & $20(2.0)$ & 0.1228 & 0.546 \\
\hline \multicolumn{6}{|l|}{$\operatorname{Sex}$} \\
\hline Male & $80(40.0)$ & $43(43.0)$ & $48(48.0)$ & 0.04777 & 0.8173 \\
\hline Female & $120(60.0)$ & $52(52.0)$ & $57(57.0)$ & 0.4777 & 1.224 \\
\hline \multicolumn{6}{|l|}{ Marital status } \\
\hline Married & $110(55.0)$ & $43(43.0)$ & $67(67.0)$ & 0.0006 & 0.37 \\
\hline Single & $56(28.0)$ & $19(19.0)$ & $37(37.0)$ & 0.0046 & 0.399 \\
\hline Divorce & $20(10.0)$ & $9(9.0)$ & $11(11.0)$ & 0.637 & 0.8 \\
\hline Separated & $4(2.0)$ & $1(1.0)$ & $3(3.0)$ & 0.312 & 0.33 \\
\hline Widowed & $10(5.0)$ & $5(5.0)$ & $5(5.0)$ & 1 & 1 \\
\hline \multicolumn{6}{|l|}{ Educational level } \\
\hline Primary & $72(36.0)$ & $25(25.0)$ & $47(47)$ & 0.0012 & 0.38 \\
\hline JHS & $52(26.0)$ & $21(21.0)$ & $31(31.0)$ & 0.106 & 0.59 \\
\hline SHS & $16(8.0)$ & $5(5.0)$ & $11(11.0)$ & 0.118 & 0.43 \\
\hline Tertiary & $6(3.0)$ & $2(2.0)$ & $4(4.0)$ & 0.41 & 0.49 \\
\hline Never & $56(28.0)$ & $23(23.0)$ & $33(33.0)$ & 0.115 & 0.6 \\
\hline \multicolumn{6}{|l|}{ Occupation } \\
\hline Farmer & $20(10.0)$ & $16(16.0)$ & $4(4.0)$ & 0.005 & 4.57 \\
\hline Fisherman & $114(57.0)$ & $49(49.0)$ & $65(65.0)$ & 0.022 & 0.52 \\
\hline Apprentice & $4(2.0)$ & $2(2.0)$ & $2(2.0)$ & 1 & 1 \\
\hline Trading & $36(18.0)$ & $11(11.0)$ & $25(25.0)$ & 0.01 & 0.37 \\
\hline Government worker & $0(0)$ & $0(0)$ & $0(0)$ & 0 & 0 \\
\hline Galamsey operator & $10(5.0)$ & $8(8)$ & $2(2.0)$ & 0.05 & 4.3 \\
\hline Unemployed & $16(8.0)$ & $12(12.0)$ & $4(4.0)$ & 0.04 & 3.27 \\
\hline
\end{tabular}

OR refers to odds ratio; $p$ value refers to level of significance. The "far from the dam" communities were Agblekame North and Agblekame South, while "near to the dam" communities were Gyama Nsuo-ano and Bongase nsuo-ano.

(Odds ratio 4.8) due to failure to treat drinking water (Table 2). The question of as to whether or not respondent saw the need to treat their water before drinking was also posed to study participants. Analysis of the results revealed that a relatively fewer proportion $(43 \%)$ of the "far from the dam" respondents were of the opinion that treatment of water before use was needless as against $45 \%$ of their "near to the dam" counterparts. Water storage behaviour of respondents in the 2 regions were compared, and the results showed that greater proportion of "far from the dam respondents" (Brong Ahafo Region) inhabitants (97\%) stored their water compared to their "near to the dam" (northern region) counterparts (86\%). The far from the dam communities also perceived the presence of debris in stored water, and the difference was significant (Table 2).

The perception of the quality of water based on some physical properties was investigated as part of our study. Analysis of the results showed that, in terms of the smell of the water, significantly greater proportion of the "far from the dam" communities (35\%) perceived that their water had an objectionable smell compared to $7 \%$ of inhabitants, their other counterparts $(p$ value $=0.001)$. The study further showed that significantly greater proportion of the study participants in the far from the communities perceived their water had colour (65\%) and they did not drink water from any other source (63\%) apart from their stream (Table 2).

The water usage patterns, water related tropical diseases infections, and the behavioural pattern of inhabitants living in 2 districts around the Black Volta were investigated. Analysis of the water usage patterns of the respondents showed that greater proportions of inhabitants from the "far from the dam" communities (18\%) had daily contact with their stream compared with just $5 \%$ of the individuals from the "near to the dam," and this was significant $(p=0.004)$. Majority of the "far from the dam" communities (97\%) also perceived that the siting of the dam had a negative effect on their health compared to those living in the "near to the dam" (86\%) (Table 3 below). The study also showed that greater proportions of the "near to the dam" dwellers (23\%) reported having been clinically diagnosed of Schistosomiasis compared to their counterparts $(2 \%)$ as shown in Table 3. With respect to malaria, the study showed that respondents from the far communities perceived that they were 4 times more at risk of getting malaria compared to those in the near end of the dam (Table 3). Our investigations further demonstrated that with regards to common symptoms of diseases frequently experienced, $11 \%$ of the "near to the dam" inhabitants often experienced coughing, whilst 37\% had 
TABLE 2: Respondents' general knowledge on their drinking water quality based on location.

\begin{tabular}{|c|c|c|c|c|c|}
\hline Variables & $\begin{array}{l}\% \text { total } \\
(200)\end{array}$ & $\begin{array}{l}\% \text { (100) far from the } \\
\text { dam communities }\end{array}$ & $\begin{array}{l}\% \text { (100) near to the dam } \\
\text { communities }\end{array}$ & $p$ value & Odd ratio \\
\hline \multicolumn{6}{|c|}{ What is the source of drinking water? } \\
\hline Stand pipe & $0(0)$ & $0(0)$ & $0(0)$ & $0(0)$ & $0(0)$ \\
\hline Borehole & $10(5.0)$ & $6(6.0)$ & $4(4.0)$ & 0.52 & 1.53 \\
\hline Stream & $144(72)$ & $87(87.0)$ & $67(67.0)$ & 0.0008 & 0.3 \\
\hline \multicolumn{6}{|l|}{ Why this source? } \\
\hline Source is closest & $62(31)$ & $39(39)$ & $23(23)$ & 0.0144 & 0.47 \\
\hline Water is reliable & $0(0)$ & $0(0)$ & $0(0)$ & $0(0)$ & $0(0)$ \\
\hline Water is clean & $0(0)$ & $0(0)$ & $0(0)$ & $0(0)$ & $0(0)$ \\
\hline Other & $138(69)$ & $49(49.0)$ & $89(89.0)$ & $<0.0001$ & 0.119 \\
\hline \multicolumn{6}{|c|}{ Is your drinking water treated? } \\
\hline Yes & $23(11.5)$ & $5(5.0)$ & $18(18.0)$ & 0.004 & 0.24 \\
\hline No & $175(87.5)$ & $95(95.0)$ & $80(80.0)$ & 0.0013 & 4.8 \\
\hline \multicolumn{6}{|c|}{ Why would you/would not treat drinking water? } \\
\hline Source is polluted & $10(5.0)$ & $3(3.0)$ & $7(7.0)$ & 0.194 & 0.41 \\
\hline Source is clean & $50(15.0)$ & $19(19.0)$ & $31(31.0)$ & 0.05 & 0.522 \\
\hline Less likely to get sick & $52(16.0)$ & $20(10)$ & $32(11.0)$ & 0.053 & 0.37 \\
\hline Debris in water & $6(30)$ & $2(2)$ & $4(4.0)$ & 1 & 1 \\
\hline \multicolumn{6}{|c|}{ Is your water stored before use? } \\
\hline Yes & $183(91.5)$ & $97(97)$ & $86(86.0)$ & 0.0993 & 5.3 \\
\hline No & $17(8.5)$ & $3(3.0)$ & $14(14.0)$ & 0.0447 & 0.28 \\
\hline \multicolumn{6}{|c|}{ If yes, do you see sediments at the bottom? } \\
\hline Yes & $127(63.5)$ & $50(50)$ & $77(77.0)$ & $<0.0001$ & 0.298 \\
\hline No & $53(26.5)$ & $47(47.0)$ & $6(6.0)$ & $<0.0001$ & 13.9 \\
\hline Sometimes & $3(1.5)$ & $0(0)$ & $3(3.0)$ & 0.081 & 0.139 \\
\hline \multicolumn{6}{|c|}{ Does your water have taste? } \\
\hline Yes & $42(21.0)$ & $7(7.0)$ & $35(35.0)$ & $<0.0001$ & 0.14 \\
\hline No & $158(79)$ & $93(93.0)$ & $65(65.0)$ & $<0.0001$ & 8.86 \\
\hline Sometimes & $5(2.5)$ & $0(0)$ & $5(5.0)$ & 0.0235 & 0.09 \\
\hline \multicolumn{6}{|l|}{ Does your water smell? } \\
\hline Yes & $160(80)$ & $97(97.0)$ & $63(63.0)$ & $<0.0001$ & 19 \\
\hline No & $40(20.0)$ & $3(3.0)$ & $37(37.0)$ & $<0.0001$ & 0.053 \\
\hline \multicolumn{6}{|c|}{ Does your water have colour? } \\
\hline Yes & $65(32.5)$ & $65(65)$ & $0(0)$ & $<0.0001$ & 0.003 \\
\hline No & $135(67.5)$ & $96(100)$ & $39(39.0)$ & $<0.0001$ & 0.003 \\
\hline \multicolumn{6}{|c|}{ Do you drink from any other source? } \\
\hline Yes & $100(50)$ & $37(37.0)$ & $63(63.0)$ & $<0.0001$ & 0.22 \\
\hline No & $100(50)$ & $63(63.0)$ & $27(27.0)$ & 0.0002 & 2.9 \\
\hline Don't know & $1(0.5)$ & $1(1.0)$ & $0(0)$ & 0.3161 & 3.03 \\
\hline
\end{tabular}

OR refers to odds ratio; $p$ value refers to level of significance. The "far from the dam" communities were Agblekame North and Agblekame South while "near to the dam" communities were Gyama Nsuo-ano and Bongase nsuo-ano.

some form of diarrhea. Meanwhile, $67 \%$ of the inhabitants often passed urine with blood and impaired vision was common in $3 \%$ of the people. These proportions were generally higher in the "near to the dam" communities compared to their "far from the dam" counterpart communities (Table 3).

Although inhabitants from both locations engaged in habitual hand washing at least 2 times a day, greater proportion of "near to the dam" dwellers (93\%) washed their hands before eating with bare hands compared to their "far from the dam" counterparts (65\%), and this was significant with $(p=0.022 ; \mathrm{OR}=0.52)$. Analysis of the responses on "how many times one visited the bathroom' showed that there were no significant differences in this particular behaviour based on ones' location (Table 3). More so, our results demonstrated that fewer proportions of "far from the dam" respondents (29\%) patronized the community dump sites compared to
$71 \%$ of their "near to the dam" communities, and the difference was statistically significant $(p<0.0001$; OR $=0.0217)$ as seen in Table 3 . The study also showed that inhabitants of "far from the dam" communities were 5 times more likely to dump their refuse in open spaces around their immediate surrounding compared to inhabitants from "near to the dam" communities as shown in Table $3(p=0.0004$; OR $=4.94)$.

The study also analysed the feacal discharge management practices of the participants. It was evident from the results that majority "near to the dam" respondents (66\%) defecated openly compared to only $27 \%$ of their counterpart as shown in Table 3 below $(p<0.0001$; OR $=5.24)$.

\section{Discussion}

Our study showed a high number of females in the "near to the dam" communities than "far from the dam" counterparts, 
TABle 3: Respondents' general knowledge of water usage patterns, water related tropical diseases, and behavioural change.

\begin{tabular}{|c|c|c|c|c|c|}
\hline Variables & $\begin{array}{l}\% \text { total } \\
(200)\end{array}$ & $\begin{array}{l}\% \text { far from the dam } \\
\text { communities }(100)\end{array}$ & $\begin{array}{l}\% \text { near to the dam } \\
\text { communities }(100)\end{array}$ & $p$ value & Odd ratio \\
\hline \multicolumn{6}{|c|}{ How often do you come into contact with water? } \\
\hline Daily & $23(11.5)$ & $18(18.0)$ & $5(5.0)$ & 0.004 & 0.24 \\
\hline Monthly & $175(87.5)$ & $95(95.0)$ & $80(80.0)$ & 0.0013 & 4.8 \\
\hline None & $2(10)$ & $0(0)$ & $2(2.0)$ & 0.1552 & 0.2 \\
\hline \multicolumn{6}{|c|}{ Do you perceive any health problem from your water? } \\
\hline Yes & $183(91.5)$ & $97(97.0)$ & $86(86.0)$ & 0.0993 & 5.3 \\
\hline No & $17(8.5)$ & $3(3.0)$ & $14(14.0)$ & 0.0447 & 0.28 \\
\hline \multicolumn{6}{|l|}{$\begin{array}{l}\text { Do you know anyone suffering from any } \\
\text { of these diseases? }\end{array}$} \\
\hline Malaria & $16(8.0)$ & $12(12.0)$ & $4(4.0)$ & 0.04 & 3.27 \\
\hline Diarrhea & $36(18.0)$ & $11(11.0)$ & $25(25.0)$ & 0.01 & 0.37 \\
\hline Onchocerciasis & $10(5.0)$ & $8(8.0)$ & $2(2.0)$ & 0.05 & 4.3 \\
\hline Schistosomiasis & $25(12.5)$ & $2(2.0)$ & $23(23.0)$ & $<0.0001$ & 0.7 \\
\hline \multicolumn{6}{|l|}{ What are possible symptoms observed? } \\
\hline Coughing & $20.0(10.0)$ & $9(9.0)$ & $11(11.0)$ & 0.0637 & 0.37 \\
\hline Diarrhea & $56(28.0)$ & $19(19.0)$ & $37(37.0)$ & 0.0046 & 0.399 \\
\hline Blood in urine & $100(55.0)$ & $43(43.0)$ & $67(67.0)$ & 0.0006 & 0.8 \\
\hline Impaired vision & $4(2.0)$ & $1(1.0)$ & $3(3.0)$ & 0.312 & 0.33 \\
\hline None & $10(5.0)$ & $5(5.0)$ & $5(5.0)$ & 1 & 1 \\
\hline \multicolumn{6}{|c|}{ How often do you wash your hands in a day? } \\
\hline 2 times & $42(21)$ & $7(7.0)$ & $35(35.0)$ & $<0.0001$ & 0.14 \\
\hline 3 times & $158(79)$ & $65(65.0)$ & $93(93.0)$ & $<0.0001$ & 8.86 \\
\hline More than 3 times & $5(2.5)$ & $0(0)$ & $5(5.0)$ & 0.0235 & 0.09 \\
\hline \multicolumn{6}{|l|}{ What do you wash your hand with } \\
\hline Soap and water & $25(12.5)$ & $2(2.0)$ & $23(23.0)$ & $<0.0001$ & 0.07 \\
\hline Only water & $84(42)$ & $34(34.0)$ & $50(50.0)$ & 0.0219 & 0.52 \\
\hline \multicolumn{6}{|l|}{ When is the washing done? } \\
\hline After eating & $106(53)$ & $33(33.0)$ & $73(73.0)$ & $<0.0001$ & 0.182 \\
\hline After visiting the toilet & $93(46.5)$ & $66(66.0)$ & $27(27.0)$ & $<0.0001$ & 5.25 \\
\hline After daily work & $1(0.5)$ & $1(1.0)$ & $0(0)$ & 0.3161 & 3.03 \\
\hline \multicolumn{6}{|l|}{$\begin{array}{l}\text { Why and how do you sometimes treat } \\
\text { your drinking water? }\end{array}$} \\
\hline When it smells bad & 0 & $0(0)$ & $0(0)$ & $0(0)$ & 0 \\
\hline By filtration to make clean & 0 & $0(0)$ & $0(0)$ & $0(0)$ & 0 \\
\hline By boiling to remove germs & $109(54.5)$ & $21(21.0)$ & $88(88.0)$ & $<0.0001$ & 0.03 \\
\hline \multirow{2}{*}{\multicolumn{6}{|c|}{ How do you keep left over food? }} \\
\hline & & & & & \\
\hline Reheat & $81(40.5)$ & $69(69.0)$ & $12(12.0)$ & $<0.0001$ & 0.06 \\
\hline In the room & $3(1.5)$ & $0(0)$ & $3(3.0)$ & 0.081 & 0.14 \\
\hline Covered & $109(54.5)$ & $21(21.0)$ & $88(88.0)$ & $<0.0001$ & 0.03 \\
\hline \multicolumn{6}{|l|}{ Where do you store the food? } \\
\hline Covered container & $160(80)$ & $97(97.0)$ & $63(63.0)$ & $<0.0001$ & 19 \\
\hline Uncovered container & $40(20.0)$ & $3(3.0)$ & $37(37.0)$ & $<0.0001$ & 0.053 \\
\hline None & 0 & $0(0)$ & $0(0)$ & $0(0)$ & 0 \\
\hline \multicolumn{6}{|c|}{ Why should food be stored when not eaten? } \\
\hline Keeps flies off & $52(26.0)$ & $21(21.0)$ & $31(31)$ & 0.106 & 0.59 \\
\hline Prevent diseases & $16(8.0)$ & $5(5.0)$ & $11(11.0)$ & 0.118 & 0.43 \\
\hline Keep food clean & $6(3.0)$ & $2(2.0)$ & $4(4.0)$ & 0.41 & 0.49 \\
\hline \multirow{2}{*}{\multicolumn{6}{|c|}{ How many time do you bath in a day? }} \\
\hline & & & & & \\
\hline One time & $20(10)$ & $11(11.0)$ & $9(9.0)$ & 0.64 & 0.8 \\
\hline Two times & $170(0.85)$ & $94(94.0)$ & $76(76.0)$ & 0.15 & 3.13 \\
\hline Never & $3(1.5)$ & $3(3.0)$ & $0(0)$ & 0.081 & 0.14 \\
\hline \multicolumn{6}{|l|}{ How do you dispose off your solid waste? } \\
\hline Burn & $102(51)$ & $15(15.0)$ & $87(87.0)$ & $<0.0001$ & 0.03 \\
\hline Community dump site & $6(6.0)$ & $2(2.0)$ & $4(4.0)$ & 1 & 1 \\
\hline Left in the open & $30(15.0)$ & $24(24.0)$ & $6(6.0)$ & 0.0004 & 4.94 \\
\hline \multicolumn{6}{|l|}{ How do you dispose of your liquid waste? } \\
\hline Lead to drain & $93(46.5)$ & $27(27.0)$ & $66(66.0)$ & $<0.0001$ & 0.3 \\
\hline Thrown on the ground & $53(26.5)$ & $47(47.0)$ & $6(6.0)$ & $<0.0001$ & 13.9 \\
\hline Thrown into the river & $3(1.5)$ & $0(0)$ & $3(3.0)$ & 0.081 & 0.14 \\
\hline
\end{tabular}

OR refers to odds ratio; $p$ value refers to level of significance. The "far from the dam" communities were Agblekame North and Agblekame South while "near to the dam" communities were Gyama Nsuo-ano and Bongase nsuo-ano. 
although there was no significant difference in their perception of the quality of drinking water. The high number of females in "near to the dam" could be due to the emergence of new female-friendly business opportunities in the area. Some studies have found that women tend to perceive a higher risk than men, particularly in cases of technological health and safety implications of risks $[11,12]$. However, our study could not find any difference in the perception of risk among the gender. The results of our study is however similar to studies by other investigators which demonstrated that women and men do not show significant difference when it comes to local environmental issues. For example, El-Zein et al. found that gender differences in expressing views about environmental concerns were a matter of sociocultural division of labor, while Howel et al. found little or no differences between gender concerning their views on the links between air pollution and health $[13,14]$. More so, Grasmuck and Scholz in a study elsewhere found no gender effect when examining the perception of heavy metal soil contamination in a community in Northwest Switzerland [15].

In this study, respondents from "near to the dam" communities who had formal education had a higher degree of knowledge of understanding on the potential impact of dams on their drinking water. They were also well abreast with activities in their environment that could result in damaging their drinking water quality. It is generally known that people who are more educated tend to be more water quality conscious. The findings of this study are however different from those of a study conducted by Larson and Edsall, where the level of education did not commensurate with knowledge of water quality concerns [16]. However, it can be argued that, in their study, most respondents were between the ages 40 to 50 and had received their education in 1970 's, where water issues in the country were generally not considered as a problem nor included in educational programs. Thus, they could not recount any educational experience related to water. Interestingly, some people in the study by Larson and Edsall still referred to water as an inexhaustible resource based on their previous education and experience. In these respondents, the old ideology about water seemed to be entrenched and difficult to change [16].

The present study also showed that the main occupational activity of both "near to the dam" and "far from the dam" communities was fishing. Some perception studies, especially those focusing on the difference in views among rural and urban residents about particular environmental aspects, take into consideration the role of place-dominant activities. For example, Salka found that as the percentage of workers in the natural resource industry increased, environmental initiatives faced more opposition [17]. Similar results are mentioned by Houghton et al. who found that persons working in extractive sector show lower levels of environmental concerns than those working in agriculture [18]. The preference of rural people for community economic growth over the environmental degradation is a function of their dependence on the extraction and use of natural resources [19].

Our study further showed that the "far from the dam" communities relied heavily on streams as sources of drinking water as opposed to their "near to the dam" communities who had other sources such as sachet and bottled water. This phenomenon could be because the "near to the dam" communities were generally more enlightened than their "far from the dam" counterpart, thus increasing their access to better drinking water. The sustainable development goal 6 seeks to ensure universal access to safe and affordable drinking water for all by 2030 [19], though several challenges are anticipated. Despite the steadily increasing supply of drinking water throughout the world, water quality continues to be of concern in many developing countries and, to a lesser extent, in developed nations [20]. In developing countries, many urban areas face the unevenness between supply and demand of reliable supply of good quality drinking water [21]. Improved access to water supply and sanitation remains one of the primary ways of addressing poor health in developing countries. Since 1990, access to drinking water coverage has expanded in subSaharan Africa by about 22\%, though it still remains low, with only $60 \%$ of the population served [19]. The challenge for water improvements also remains greater for most subSaharan African countries, where coverage is mostly below average. In many developing countries, insufficient access to clean water and adequate sanitation and the resulting health issues are acute problems. Every year, the lack of safe water, sanitation, and hygiene cause about $88 \%$ of deaths from diarrheal diseases, accounting for 1.5 million such deaths-majority of which occur among children under the age of 5 [22]. To win any health battles, in developing countries, therefore, secure, clean water and sanitation facilities for all should be a government priority. Health psychologists recognize the perceived risk of illness as one of the most important factors in a household's precautionary behaviours [23].

This study again showed that majority of "far from the dam" respondents did not treat their drinking water compared to their upstream counterpart. Without safe public water supplies, households' health and well-being are at risk. Domestic water treatment has been shown to be one of the most effective means of reducing the risks and costs associated with preventing water-borne diseases, especially diarrhea [24]. However, despite the importance of increasing water quality through domestic treatment, empirical research remains scarce on the relationship between water treatment and factors such as risk perception that drive this decision. There appear to be few studies focusing on the above issues. Notable exceptions are those by Cai et al., Jakus et al., and Nauges and van den Berg [25-27]. Nauges and van den Berg studied the perception of health risk and averting behaviour for nonpipe water sources in Sri Lanka [27]. Jakus et al. examined the rationale behind people in the United States (US) buying bottled water [26], while Cai et al. explored altruistic averting behaviour of removing arsenic risk in drinking water in the US [25].

This result confirmed the important role perceived risk plays in changing health behaviour, as found in earlier studies that provided risk information $[28,29]$. These results also resonates with previous findings by Nauges and van den Berg that households were aware that treating nonpiped 
water lowers the risks related to the consumption of unimproved water [27]. The results of their study further suggested that the probability of treating water decreases if the head of the household or the respondent was male. Males were $21 \%$ less likely than females to treat nonpiped unimproved drinking water. One possible explanation was that women, who were generally responsible for taking care of children in the study areas, might have found it more worthwhile to treat water to avoid water-borne diseases, for example. These results are in line with experimental measures of risk aversion studies, where it is often found that women are more risk-averse than men [30].

Our findings on respondent perception of the quality of water with respect to the construction of the Bui dam based on some physical properties showed that significantly greater proportion of the "far from the dam" communities perceived their drinking water had an objectionable smell compared to "near to the dam" communities counterpart. Inhabitants perceived that the creation of the Bui Dam had caused great loss to vegetation and caused aquatic and terrestrial organisms to be submerged. However, the deterioration of the water quality in the downstream of the Bui subbasin could be attributed to the decay of dead animals and plants in the water from the time the research was being carried out. The physicochemical parameters of some dams and reservoirs have been studied in pre- and postimpoundment conditions [31]. However, studies on the tropical regulated downstream river of dams are limited though it is also subjected to major environmental impacts ranging from downstream morphological changes to change in biodiversity of the ecosystem. Downstream impacts of the dam can sometimes extend up to a distance of about $100 \mathrm{~km}$ from the dam site [32], although the intensity of the impacts tends to decline with increasing distance from the dam site. Dams can also change downstream hydrology by altering the flow pattern which and this changes the water quality of the downstream river [33].

The perceived high prevalence of water-related diseases in younger children and older females could be due to their regular visit to their source of water, fetching with buckets for drinking and/or other domestic purposes (older women) or to swim for younger children. In the Black Volta basin of Bui Dam, inhabitants perceived that impoundment of Bui River created the opportunity for growth of aquatic weeds in some areas and also the influx of immigrants (fishermen already infested with Bilhazia disease) schistosomiasis (also known as bilharzia, disease caused by parasitic worms of the genus Schistosoma) [34]. The economic and health effects of schistosomiasis are considerable, and the disease disables more than it kills. In children, schistosomiasis can cause anaemia, stunting, and a reduced ability to learn, although the effects are usually reversible with treatment. Chronic schistosomiasis may affect people's ability to work and in some cases can result in death. The number of deaths due to schistosomiasis currently is difficult to estimate because of hidden pathologies such as liver and kidney failure as well as bladder cancer. Elsewhere, the emergences or reemergence of schistosomiasis has resulted from large-scale hydropower projects, e.g., Gezira-Managil Dam (Sudan), Aswan Dam
(Egypt), Melkasadi Dam (Ethiopia), and the Danling and Huangshi Dams (China) [35]. Similarly, changes in water level and downstream sediment deposition resulting from the building of the Three Gorges Dam in China seemed to increase the schistosomiasis transmission season within the marshlands along the middle and lower reaches of China's Yangtze River [36].

From our study, "far from the dam" dwellers reported relatively low biting frequency of the black fly insects after the construction of the Bui Dam. This is positive because Black Volta basin of the Bui Dam is known to be heavily infested with black fly insects. The reportedly reduced abundance of the black fly population could be attributed to the Bui river impoundment in the Bui subbasin of the Black Volta. These black flies breed along fast-flowing rivers and streams, close to remote villages located near fertile land where people rely on agriculture [37]. The black flies are vectors of river blindness, a neglected tropical disease (NTD) caused by infection with the parasitic worm Onchocerca volvulus. The burden of the disease has been reduced by prevention efforts, including control of the fly vector and periodic ivermectin therapy in at-risk individuals.

This study also proved that "far from the dam" inhabitants' perceived they were 4 times more at risk of getting sick with malaria than their "close to the dam" counterparts. This could be attributed to the fact that the people living in the "near to the dam" communities resided closer to the Bui Dam where there was a high possibility that inhabitants could have contact with mosquitoes. Malaria is a mosquitoborne infectious disease affecting humans and other animals caused by parasitic protozoans (a group of single-celled microorganisms) belonging to the Plasmodium type [37, 38].

Further, our study also showed that the practice of environmental hygiene was better in "far from the dam" communities as against their "near to the dam counterpart" counterparts. Though "near to the dam counterpart" inhabitants had containers they could dispose their solid waste into, they often disregarded this activity by disposing their solid waste directly in their environs with key examples being fishmongers. The worst offenders of these were fishermen who lived closer to the river banks and depended on this source of water for their livelihood. Hygiene has been found to be a primary preventive measure against diarrhea [38]. Even though water supply and sanitation impact on diarrhea, hygiene measures further minimize the effect of poor water supply and poor sanitation on diarrhea [22]. A lot of studies have pinpointed the effects of hygiene on disease transmission. Mara (2003) suggested that hygiene is potentially one of the most effective means of reducing the global burden of diarrhea diseases in children [39]. Waste that is not properly managed, especially excreta and other liquid as well as solid waste from households and communities, constitutes a serious house health hazard which tends to spread infectious diseases. Unattended waste lying around attracts flies, rats, and other creatures that in turn spread disease. Normally, this is a result of the wet waste that decomposes and releases bad odour [39]. The category of people who are more likely to dispose solid waste include the population in areas where there is no proper waste disposal 
sites, especially school children and workers in facilities producing toxic and infectious materials. Organic domestic wastes also pose a serious threat since they ferment creating conditions favourable to the survival and growth of microorganisms.

\section{Conclusion}

This study sought to investigate the perceptions of the participants about the impacts of the construction of the Bui Dam on their communities. The study demonstrated that generally, inhabitants "near to the dam" communities perceived the construction of the Bui Power Project has negatively affected their drinking water quality as well as their health. The perception of the negative impacts of the dam increased with proximity to the dam site. However, since perceptions of risks do not translate into empirical evidence on the actual impact of the dam, it is important to urgently carry out studies needed to ascertain whether these perceptions are the reality so that remediating measures could be put in place.

\section{Data Availability}

The authors declare that data for this work will be available upon reasonable request.

\section{Conflicts of Interest}

The authors declare that they have no conflicts of interest.

\section{Acknowledgments}

We are grateful to the people and opinion leaders of the study community for giving us assessment and participating in this study. We are also grateful to Dr. Eric Ofosu for enormous support and guidance provided in the course of the study.

\section{References}

[1] M. Mul, L. Pettinotti, N. A. Amonoo, E. Bekoe-Obeng, and E. Obuobie, Dependence of Riparian Communities on Ecosystem Services in Northern Ghana, International Water Management Institute (IWMI), Colombo, Sri Lanka, 2018.

[2] F. Hossain, A. M. Degu, W. Yigzaw et al., "Climate feedback-based provisions for dam design, operations, and water management in the 21st century," Journal of Hydrologic Engineering, vol. 17, no. 8, pp. 837-850, 2012.

[3] M. Ho, U. Lall, M. Allaire et al., "The future role of dams in the United States of America," Water Resources Research, vol. 53, no. 2, pp. 982-998, 2017.

[4] G. Siciliano, F. Urban, M. Tan-Mullins, and G. Mohan, "Large dams, energy justice and the divergence between international, national and local developmental needs and priorities in the global South," Energy Research and Social Science, vol. 41, pp. 199-220, 2018.

[5] D. Tullos, "Assessing the influence of environmental impact assessments on science and policy: an analysis of the three gorges project," Journal of environmental management, vol. 90, no. 3, pp. S208-S223, 2008.
[6] Z. J. Grabowski, A. Denton, M. A. Rozance, M. Matsler, and S. Kidd, "Removing dams, constructing science: coproduction of undammed riverscapes by politics, finance, environment, society and technology," Water Alternatives, vol. 10, no. 3, pp. 769-795, 2017.

[7] Ghana Dams Forum, Issues on Compensation of Dam Affected People, Kalitsi and Associate, Accra, Ghana, 2008.

[8] A. Azara, U. Mosiato, and I. Mura, Disponibilità di Acqua Potabile, Rapporto Osservasalut, Rome, Italy, 2010.

[9] M. Dettori, A. Piana, P. Castiglia, E. Loria, and A. Azara, "Qualitative and quantitative aspects of drinking water supply in Sardinia, Italy. A descriptive analysis of the ordinances and public notices issued during the years 2010-2015," Annali di Igiene, vol. 28, no. 4, pp. 296-303, 2016.

[10] Ghana Statistical Service, 2010 Population and Housing Census Final Results, 2012, http://www.statsghana.gov.gh/ pop_stats.html.

[11] G. Yapici, O. Ögenler, A. Ö. Kurt, F. KoçaG, and T. FaGmaz, "Assessment of environmental attitudes and risk perceptions among university students in Mersin," Journal of Environmental and Public Health, vol. 2017, Article ID 5650926, 8 pages, 2017.

[12] A. Bianco, G. A. Carmelo, F. Gnisci, and M. Pavia, "Knowledge and perceptions of the health effects of environmental hazards in the general population in Italy," International Journal of Hygiene and Environmental Health, vol. 211, no. 3-4, pp. 412-419, 2008.

[13] A. El-Zein, R. Nasrallah, I. Nuwayhid, L. Kai, and J. Makhoul, "Why do neighbors have different environmental priorities? Analysis of environmental risk perception in a beirut neighborhood," Risk Analysis, vol. 26, no. 2, pp. 423-435, 2006.

[14] D. Howel, S. Moffatt, J. Bush, C. E. Dunn, and H. Prince, "Public views on the links between air pollution and health in Northeast England," Environmental Research, vol. 91, no. 3, pp. 163-171, 2003.

[15] D. Grasmuck and R. W. Scholz, "Risk perception of heavy metal soil contamination by high-exposed and low-exposed inhabitants: the role of knowledge and emotional concerns," Risk Analysis, vol. 25, no. 3, pp. 611-622, 2005.

[16] K. L. Larson and R. M. Edsall, "The impact of visual information on perceptions of water resource problems and management alternatives," Journal of Environmental Planning and Management, vol. 53, no. 3, pp. 335-352, 2010.

[17] W. M. Salka, "Urban-rural conflict over environmental policy in the western United States," American Review of Public Administration, vol. 31, no. 1, pp. 33-48, 2001.

[18] A. Houghton, J. Austin, A. Beerman, and C. Horton, "An approach to developing local climate change environmental public health indicators in a rural district," Journal of Environmental and Public Health, vol. 2017, Article ID 3407325, 16 pages, 2017.

[19] WHO and UNICEF, WHO/UNICEF Joint Monitoring Programme (2017) Report, 2017, https://washdata.org/report/ jmp-2017-report-launch-version0.

[20] UNDP, UNDP Annual Report 2006: Global Partnership for Development, 2006, http://www.undp.org/content/undp/en/ home/librarypage/corporate/undp_in_action_2006.html.

[21] G. Soto Montes de Oca and I. J. Bateman, "Scope sensitivity in households' willingness to pay for maintained and improved water supplies in a developing world urban area: Investigating the influence of baseline supply quality and income distribution upon stated preferences in Mexico 
City," Water Resources Research, vol. 42, no. 7, article W07421, 2006.

[22] UNICEF, Water, Sanitation and Hygiene Annual Report (2008), 2008, https://www.unicef.org/.../UNICEF_WASH_ 2008_Annual_Report_Final_27_05_2009.pdf.

[23] C. A. Redding, J. S. Rossi, S. R. Rossi et al., "Health behavior models," International Electronic Journal of Health Education, vol. 3, pp. 180-193, 2000.

[24] T. Clasen, I. Roberts, T. Rabie, W. Schmidt, and S. Cairncross, "Interventions to improve water quality for preventing diarrhoea (a cochrane review)," in The Cochrane Library, Update Software, Oxford, UK, 2006.

[25] Y. Cai, W. D. Shaw, and X. Wu, "Risk perception and altruistic averting behavior: removing arsenic in drinking water," in Proceedings of American Agricultural Economics Association Annual Meeting, Orlando, FL, USA, July 2008.

[26] P. M. Jakus, W. D. Shaw, T. N. Nguyen, and M. Walker, "Risk perceptions of arsenic in tap water and consumption of bottled water," Water Resources Research, vol. 45, article W05405, 2009.

[27] C. Nauges and C. van den Berg, "Perception of health risk and averting behavior: an analysis of household water consumption in southwest Sri Lanka," Working Paper 08.09.253, Toulouse School of Economics (LERNA-INRA), Toulouse, France, 2006.

[28] J. Jalan and E. Somanathan, "The importance of being informed: experimental evidence on demand for environmental quality," Journal of Development Economics, vol. 87, no. 1, pp. 14-28, 2008.

[29] M. Madajewicz, A. Pfaff, A. van Geen et al., "Can information alone both improve awareness and change behavior? Arsenic contamination of groundwater in Bangladesh," Journal of Development Economics, vol. 84, no. 2, pp. 731-754, 2007.

[30] C. C. Eckel and P. J. Grossman, "Men, women and risk aversion: experimental evidence," in Handbook of Experimental Economics Results, pp. 1061-1073, Elsevier, New York, NY, USA, 2008.

[31] T.Y. Ling, L. Nyanti, T. Muan et al., "Physicochemical parameters of bakun reservoir in Belaga, Sarawak, Malaysia, 13 months after reaching full supply level," Sains Malaysiana, vol. 45, no. 2, pp. 157-166, 2016.

[32] Y. Zhang, J. Xia, T. Liang, and Q. Shao, "Impact of water projects on river flow regime sand water quality in Huai River Basin," Water Resources Management, vol. 24, no. 5, pp. 889-908, 2010.

[33] Q. Zhao, S. Liu, L. Deng et al., "Landscape change and hydrologic alteration associated with dam construction," International Journal of Applied Earth Observation and Geoinformation, vol. 16, no. 1, pp. 17-26, 2012.

[34] A. D. Ziegler, T. N. Petney, C. Grundy-Warr et al., "Dams and disease triggers on the lower Mekong river," PLoS Neglected Tropical Diseases, vol. 7, no. 6, article e2166, 2013.

[35] D. P. McManus, D. J. Gray, Y. Li et al., "Schistosomiasis in the People's Republic of China: the era of the three gorges dam," Clinical Microbiology Reviews, vol. 23, no. 2, pp. 442-466, 2010.

[36] T. N. Petney and H. Taraschewski, "Water-borne parasitic diseases: hydrology, regional development and control," in Treatise on Water Science, F. H. Frimmel, Ed., vol. 3, pp. 303-366, Elsevier, New York, NY, USA, 2011.

[37] World Health Organization, World Malaria Report 2014, 2014, http://www.who.int/malaria/publications/world_malaria...2014/ wmr-2014-no-profiles.pdf.
[38] World Health Organization, Geneva: International Travel and Health, 2004, http://www.who.int/ith/en/.

[39] D. Mara, Domestic Wastewater Treatment in Developing Countries, 2003, https://www.pseau.org/outils/ouvrages/ earthscan_ltd_domestic_wastewater_treatment_in_developing countries_2003.pdf. 


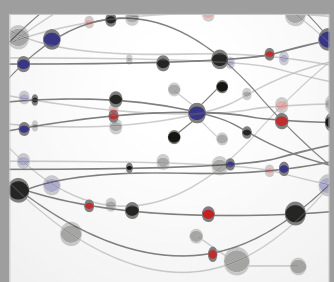

The Scientific World Journal
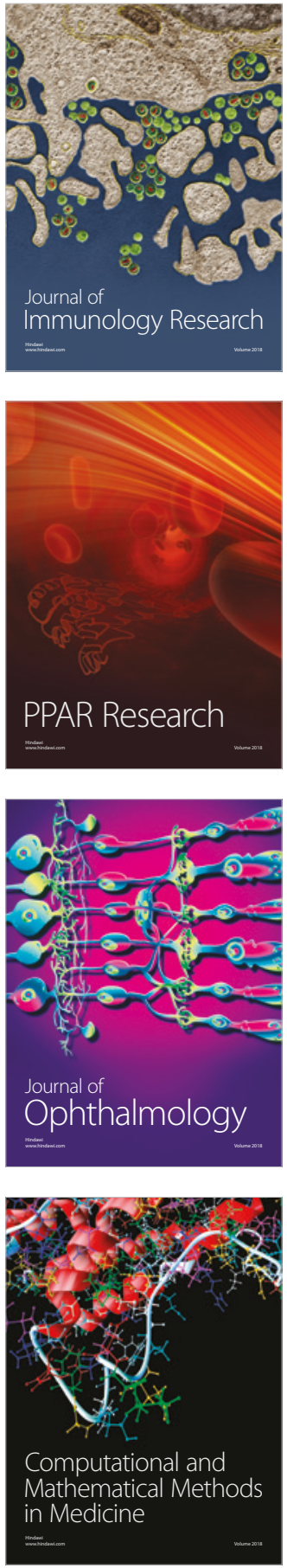

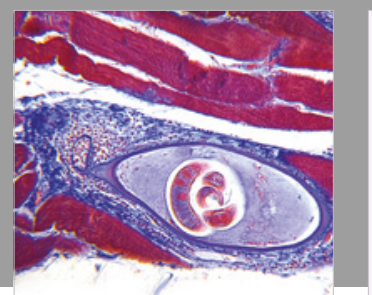

Gastroenterology Research and Practice

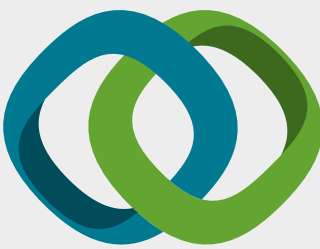

\section{Hindawi}

Submit your manuscripts at

www.hindawi.com
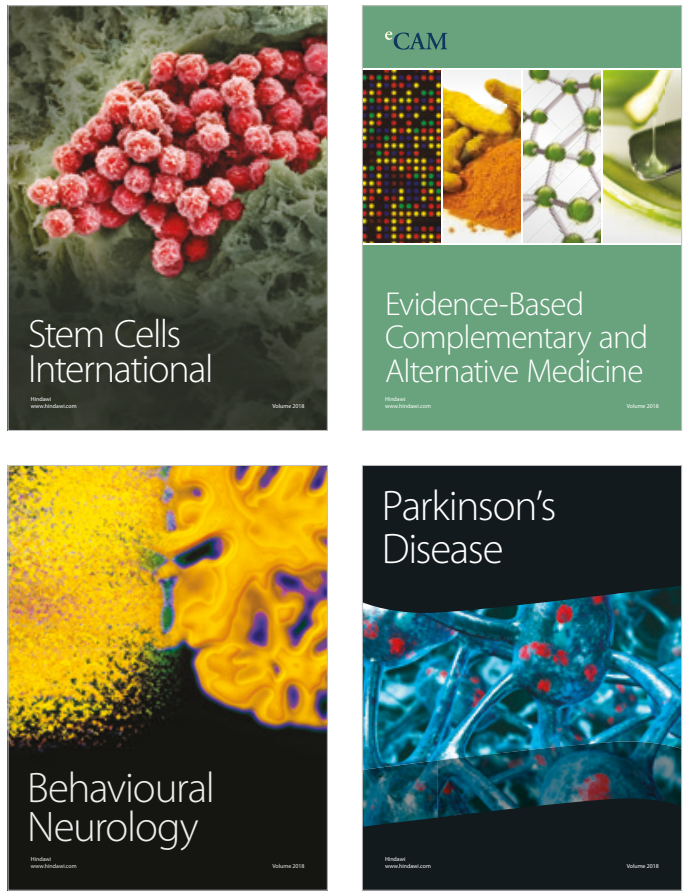

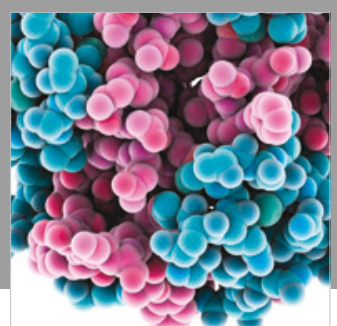

ournal of

Diabetes Research

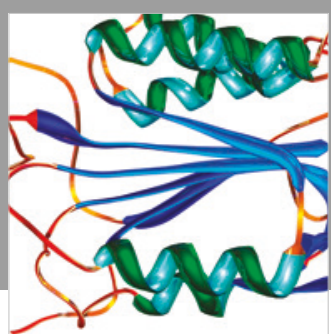

Disease Markers
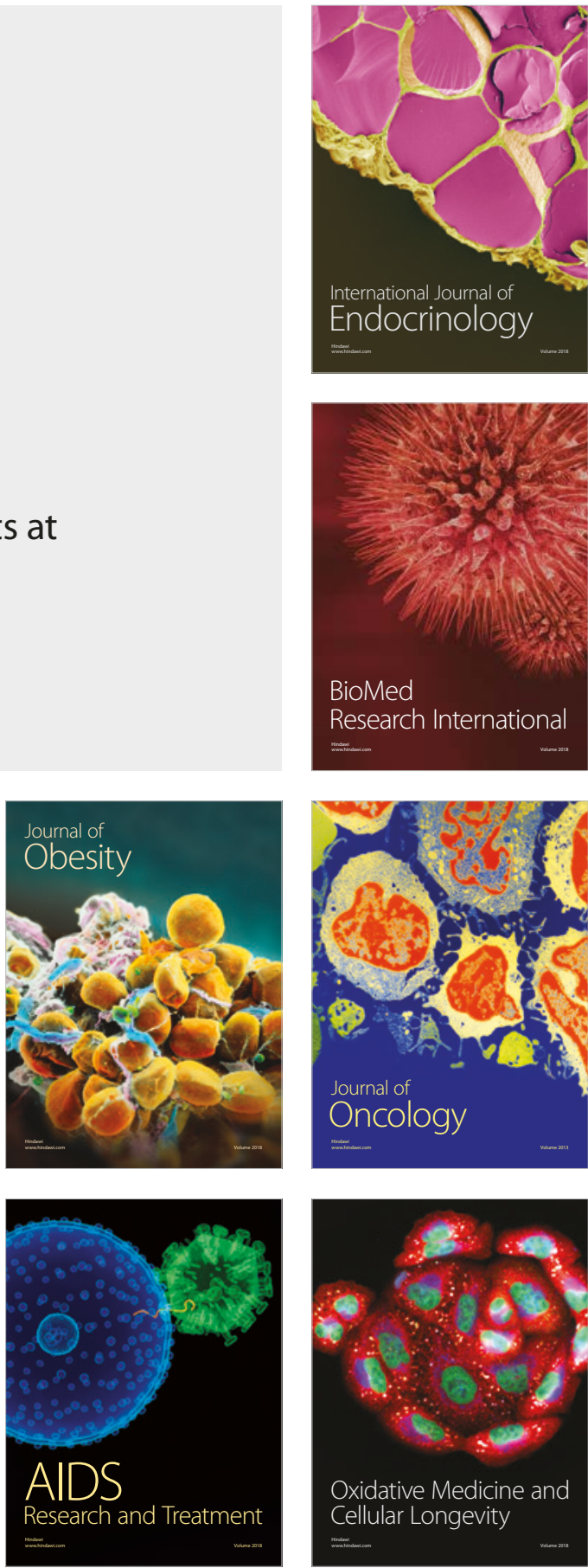